\title{
Current management of anal fistulas in Crohn's disease
}

\author{
Jacek Hermann¹, Piotr Eder², Tomasz Banasiewicz'1, Konrad Matysiak ${ }^{1}$, Liliana Łykowska-Szuber ${ }^{2}$ \\ ${ }^{1}$ Chair and Department of General and Endocrinological Surgery and Gastroenterological Oncology, Poznan University \\ of Medical Sciences, Poznan, Poland \\ ${ }^{2}$ Chair and Department of Gastroenterology, Human Nutrition, and Internal Medicine, Poznan University of Medical Sciences, \\ Poznan, Poland
}

Prz Gastroenterol 2015; 10 (2): 83-88

DOI: $10.5114 /$ pg.2015.49684

Key words: Crohn's disease, anal fistula, combined therapy.

Address for correspondence: Jacek Hermann MD, Chair and Department of General and Endocrinological Surgery and Gastroenterological Oncology, Poznan University of Medical Sciences, 49 Przybyszewski St, 60-355 Poznan, Poland, phone: +48 618691275 , fax: +48 618691684 , e-mail: jacekhermann@gmail.com

\begin{abstract}
Anal fistulas occurring in Crohn's disease (CD) comprise a risk factor of severe course of inflammation. They are frequently intractable due to various factors such as penetration of the anal canal or rectal wall, impaired wound healing, and immunosuppression, among others. Anal fistulas typical to CD develop from fissures or ulcers of the anal canal or rectum. Accurate identification of the type of fistula, such as low and simple or high and complex, is crucial for prognosis as well as for the choice of treatment. If fistulotomy remains the gold standard in the surgical treatment of the former, it is contraindicated in high and complex fistulas due to possible risk of damage to the anal sphincter with subsequent faecal incontinence. Therefore, the latter require a conservative and palliative approach, such as an incision and drainage of abscesses accompanying fistulas or prolonged non-cutting seton placement. Currently, conservative, sphincter-preserving, and definitive procedures such as mucosal advancement or dermal island flaps, the use of plugs or glue, video assisted anal fistula treatment, ligation of the intersphincteric track, and vacuum assisted closure are gaining a great deal of interest. Attempting to close the internal opening without injuring the sphincter is a major advantage of those methods. However, both the palliative and the definitive procedures require adjuvant therapy with medical measures.
\end{abstract}

\section{Introduction}

Anal fistulas occurring in Crohn's disease (CD) comprise a risk factor of severe course of inflammation. They are frequently intractable due to various factors such as penetration of the anal or rectal wall by the inflammatory process, impaired wound healing, and immunosuppression, among others. Standardised management of those lesions has not yet been established.

The aim of the paper was a review of modern methods of treatment of anal fistulas in CD on the basis of the authors' experience and available literature $[1,2]$.

\section{Aetiology}

Anal fistulas typical to CD develop from fissures or ulcers penetrating the anal canal or rectal wall. Increased pressure within the anal canal force faeces into the perianal or perirectal, and finally the subcutaneous tissues, resulting in fistula formation. However, fistulas in CD may also develop, similar to sporadic fistulas, due to infection of the Hermann's anal glands. Therefore, the lesions may be divided into cryptogenic or non-cryptogenic fistulas [3, 4].

\section{Incidence}

Anal fistulas occur in $20 \%$ of patients suffering from CD. About $12 \%$ of patients with small bowel inflammation are affected by anal fistulas: $15 \%$ with the ileocecal form of the disease, and $41 \%$ of those with Crohn's colitis. Finally, almost all patients with inflammation within both the rectum and colon develop anal fistulas [1, 2].

\section{Classification}

Parks' classification of anal fistulas is commonly used in practice today. It relies on topography of the 
fistulous track and the anal sphincters. Another division is composed of low fistulas, originating below the dentate line, and high fistulas, emerging above that line. There is another classification on which basis simple fistulas develop a single canal and only one external orifice. However, complex fistulas are composed of secondary branches and multiple external openings. Finally, fistulas involving more than the lower third of the sphincter circuit, anterior fistulas in women, recurrent lesions, fistulas accompanied by abscesses, or proctitis, or faecal incontinence, or anal, rectal strictures, are also recognised as complex. Accurate identification of the type of a fistula is crucial for prognosis as well as for the choice of the method of treatment [5].

\section{Diagnosis}

Digital rectal examination remains the gold standard in the diagnosis of anal fistulas. Examination under general anaesthesia is indicated in patients affected by severe and painful inflammation of the perianal region. The topography of a fistula and the internal opening is recognised with insertion of probes into the fistulous track, sometimes with the assistance of peroxide water or methylene blue injected into the canal through the external opening. Magnetic resonance imaging and anorectal ultrasonography are considered as complementary methods of radiological diagnosis, mostly in recurrent and complex fistulas complicated with abscesses [5, 6].

\section{Classical surgery}

Conservative approach is a principle rule that should be obeyed in the surgical treatment of anal fistulas in $C D$ due to the high rate of recurrence, impaired wound healing, and possible risk of damage to the anal sphincter with subsequent faecal incontinence after several surgical interventions. The main aim of the treatment is alleviation of severe pain by incision and drainage of abscesses concomitant with fistulas with preservation of proper sphincter function. Therefore, treatment of anal fistulas in CD is more alleviative then radical $[7,8]$.

The treatment of fistulas should be preceded by careful examination, and intensive medication if necessary, of possible inflammatory changes in more proximal segments of the bowel, mostly in the rectum [9]. Superficial perianal abscesses should be drained with a relatively small radial incision close to the anus to shorten possible future fistulous track. In the case of deeper perirectal abscesses Pezzer's tubes should be left in the cavities [10].

Non-cutting setons should be placed in the fistulous track for months to prevent the patients from recurrent infection and puss collection. A loose seton is a surgi- cal thread that is introduced into the fistulous canal from the external to internal opening and tied with no tension. That seton promotes healing of a fistula from the internal opening instead of the external one without jeopardising the function of the sphincter. In turn, cutting setons are not recommended due to the risk of damage to the sphincter or deformation of the anus [11].

Fistulotomy is exceptionally acceptable in the treatment of superficial and low inter-sphincteric fistulas, unfortunately relatively less common in CD compared to cryptogenic ones. A two-stage procedure is recommended in low trans-sphincteric fistulas. It consists of dissection of a fistulous track except for the trans-sphincteric part of the track, and mobilisation of the affected portion of the sphincter around which a loose seton is left. That encircled part of the sphincter is transected, a few weeks after which fibrosis of the muscle appears to prevent retraction of sphincter remnants. The success rate reaches $90 \%$ if proctitis is excluded. Faecal incontinence of various degrees is declared by a few per cent of the patients [12-16].

High and complex fistulas continue to be a challenge to surgeons. Because fistulotomy is contraindicated in those fistulas, most of the patients require palliative treatment [17]. Most surgeons prefer non-cutting setons, which are left in place for months until inflammation recedes. Alleviation of pain, decreasing discharge from the fistulous orifice, reduction of perianal skin induration, and narrowing of a fistulous track to the diameter of a seton indicate resolution of inflammation on a clinical basis. In such circumstances removal of a seton is acceptable with possible healing of the fistula. Recurrence of the complication occurs in $40-80 \%$ of patients. Therefore, a small group of patients with high and complex fistulas may undergo definitive treatment of a fistula after resolution of inflammation and healing of proctitis. Currently available sphincter preserving methods can be introduced $[15,18,19]$. Patients with recurrent and retractable fistulas, and severe proctitis are scheduled for temporary loop-ileostomy, in most cases for life [20]. Abdomino-perineal resection of the rectum is performed in $10-18 \%$ of patients for recurrent, intractable perianal abscesses and fistulas, anal or rectal strictures, and irreversible damage of the anal sphincter $[13,21]$.

\section{Definitive surgical treatment}

There is an attempt nowadays to offer patients with high and complex fistulas, besides the aforementioned palliative management, definitive treatment with sphincter-preserving procedures such as mucosal advancement or dermal island flaps, the use of glue or plugs, video assisted anal fistula treatment, ligation of inter-sphincteric track, and vacuum assisted clo- 
sure. Attempting to close the internal opening without jeopardising the function of the sphincter is a major purpose of these modern procedures. However, sphincter-saving operations should be preceded by prolong drainage with a non-cutting seton until inflammation within the fistulous track recedes [15].

\section{Mucosal advancement or dermal island flaps}

The internal opening is excised and the wound sutured with following closure of the fistulous track with advanced mucosal and muscular flap mobilised from the rectum. The rectal flap, responsible at times for mucosal ectropion, can be replaced with an anodermal one. Although early results of the procedure are encouraging, the late recurrence rate is $50 \%$, whereas postoperative faecal incontinence hovers between $10 \%$ and $20 \%$ [22].

\section{Glue}

A fistulous track is sealed with either fibrin or synthetic glue. The glue is introduced starting from the external opening. The procedure is preceded by curettage of the fistulous canal. A major advantage of this method is preservation of the sphincter, the possibility of repeating it in the event of failure, and implementation of more aggressive methods of surgery in the future if necessary. Low efficacy of glue sealing, estimated at $14-60 \%$, is a major drawback of that method [23].

\section{Plugs}

The plug is a bio-absorbable prosthesis made from porcine intestinal submucosa. It serves as stroma for host cell remodelling. After debridement of the fistulous track a plug is introduced into the track through the internal orifice until it becomes stuck. Finally, the prosthesis is anchored with several sutures to the internal sphincter near the internal orifice and the mucosa is closed over the plug. The external opening is left open to allow drainage. The advantages of this method are similar to those of glue sealing. The efficacy of this method is estimated at around 50\% [24].

\section{Video-assisted anal fistula treatment}

An advantage of video-assisted anal fistula treatment is an accurate debridement of the fistulous track from inflammatory granulation tissue under sight control, identification of secondary tracks, and closure of the internal opening with a dedicated stapling device. The row of staples is reinforced with synthetic glue, which is introduced through the external orifice. Equipment costs are a major disadvantages of this method of treatment [25].

\section{Ligation of the inter-sphincteric fistulous track}

The space between the internal and external sphincters is opened with a curved incision laterally to the inter-sphincteric groove. The track localised within that space is mobilised, excised, and both remnants are ligated. In addition, the external part of the track is curetted. In other words, during that procedure the trans-sphincteric fistula is replaced with the inter-sphincteric one. The latter one is then transected. The efficacy of this method is estimated at 60-90\% [26].

\section{Negative pressure wound therapy}

Negative pressure therapy seems to be particularly justified in the treatment of complex anal fistulas. It allows for the continuous and effective drainage of wounds, and a reduction of inflammation. Negative pressure within the excised external orifice and the track provides good conditions for closure of the canal and development of granulation tissue. Application of the dressing is preceded with curettage of the track. Protection of the negative pressure dressing (located in the perianal region) from leakage remains one of the most important obstacles of the treatment [27]. Excision of an anal fistulous tack in a patient with CD, consecutive stages of the negative pressure wound dressing application in the perianal region, and the final result of treatment are shown in Figures 1-5.

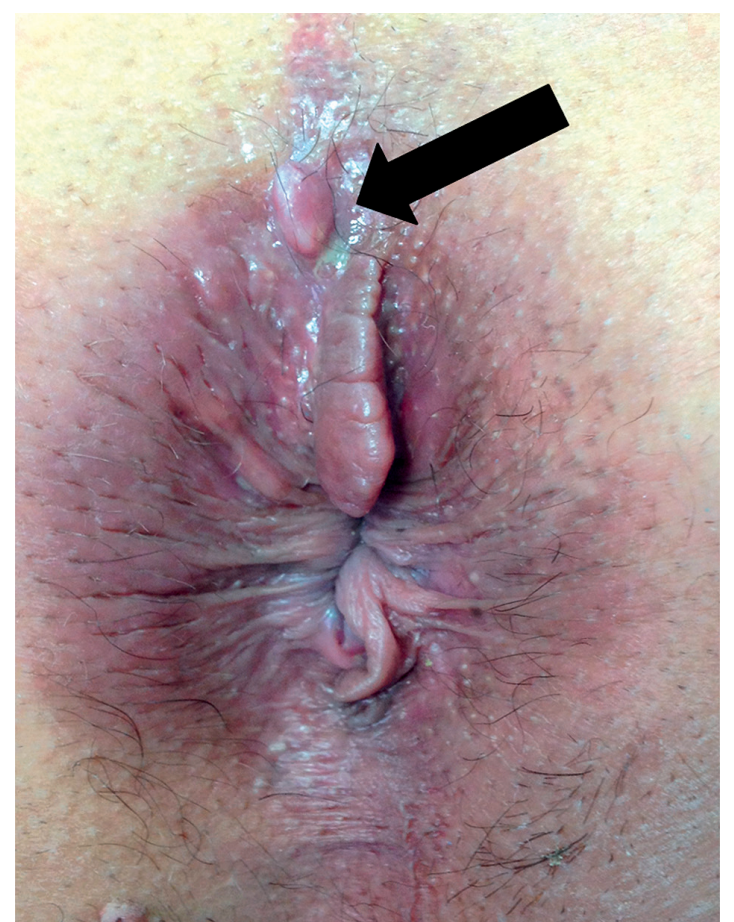

Figure 1. External orifice (arrow) of a trans-sphincteric anal fistula in a patient with $C D$ 


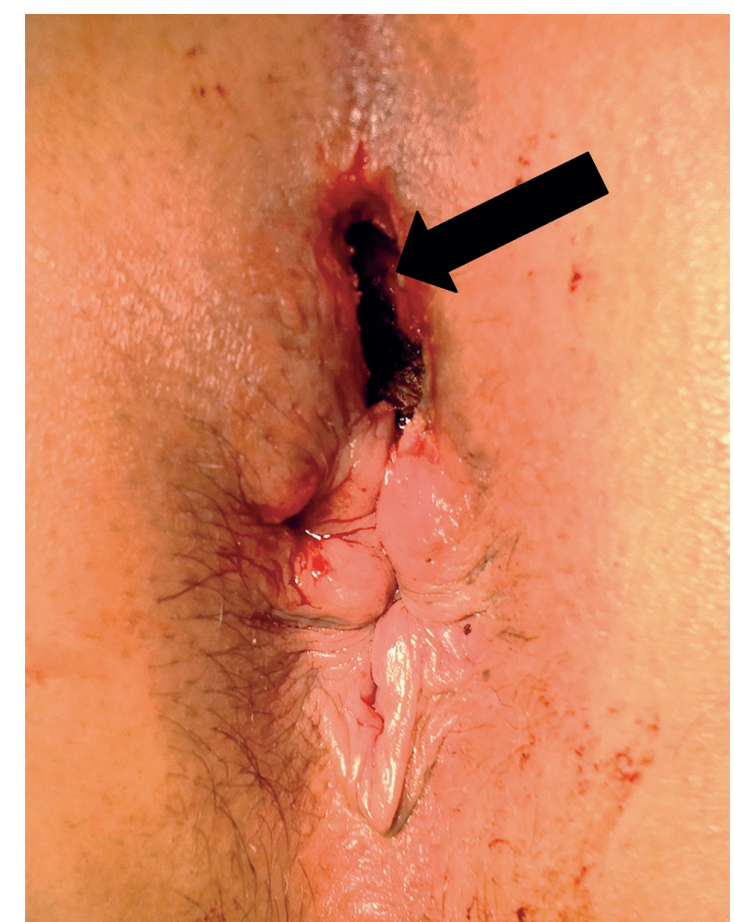

Figure 2. Wound after excision of the fistulous canal and external orifice (arrow) with the anal sphincter left intact

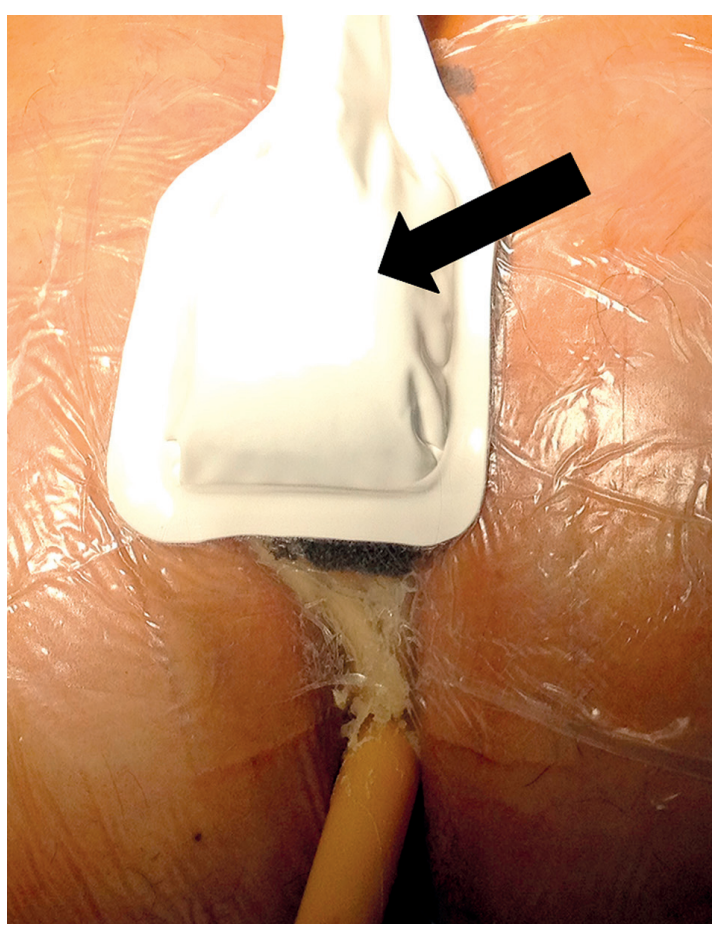

Figure 4. A vacuum pad (arrow) secured to the negative pressure wound dressing under continuous pressure of $100 \mathrm{~mm} \mathrm{Hg}$

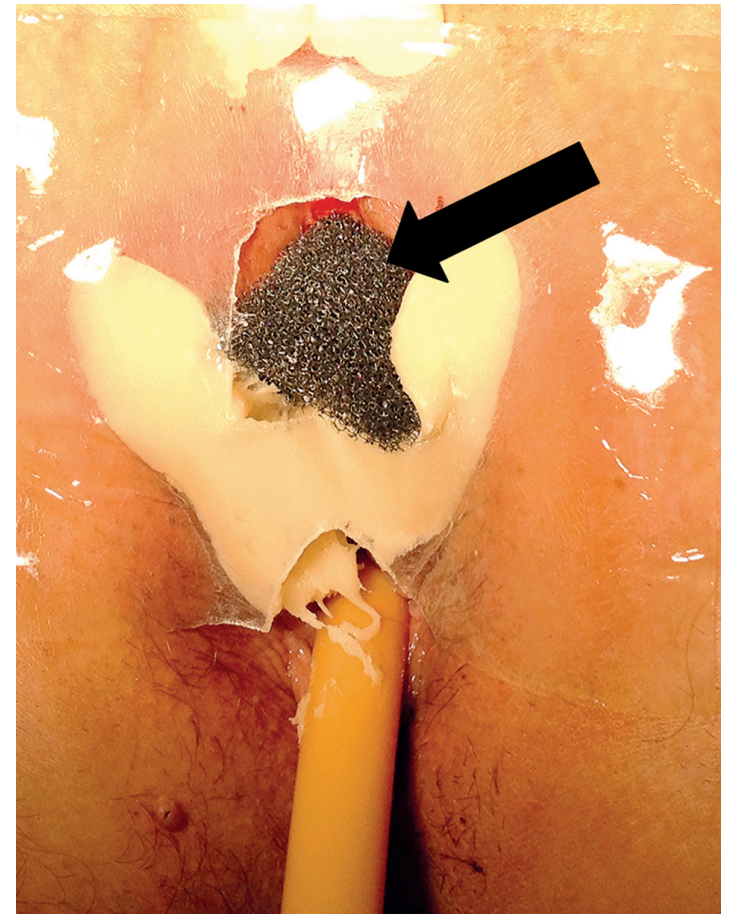

Figure 3. A polyurethane sponge (arrow) introduced to the wound and secured to the perianal skin with a double-sided adhesive silicon plate and stoma paste

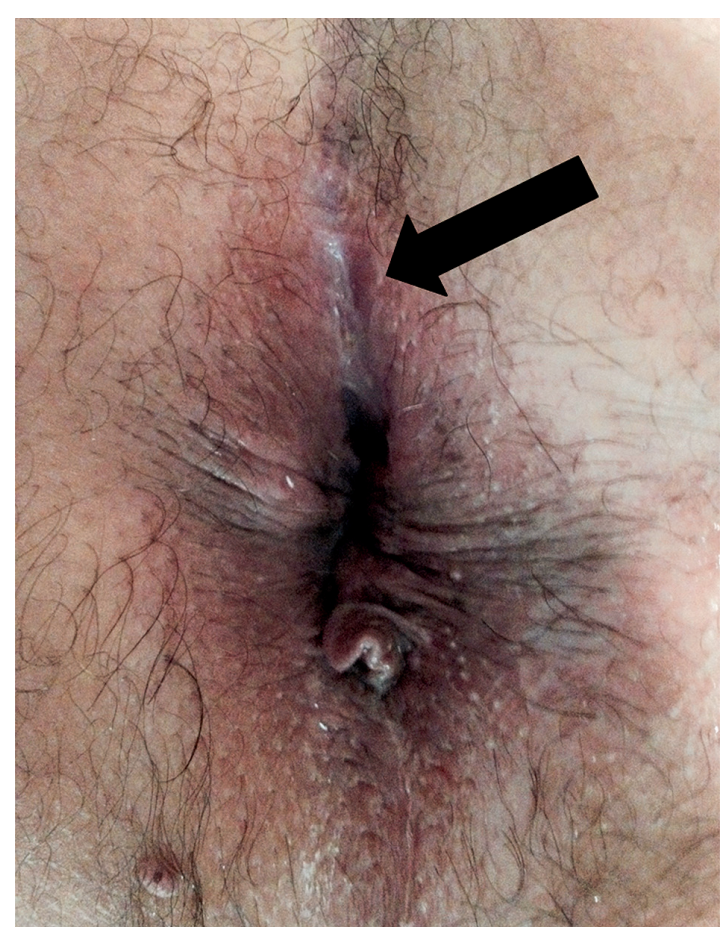

Figure 5. A postoperative scar 2 months after application of the negative pressure wound dressing 


\section{Adjuvant medical therapy}

Surgical treatment of anal fistulas is combined today with medical measures, according to the current guidelines of the European Crohn's and Colitis Organization (ECCO) as well as the Polish guidelines [28, 29]. Antibiotics and thiopurines such as azathioprine and 6-mercaptopurine are first-line medications in complex anal fistulas, but only thiopurines can be used as a maintenance therapy in order to sustain clinical remission. The introduction of novel biological therapies is considered to be a milestone in therapeutic regimens in CD. Biological agents are monoclonal antibodies or fusion proteins that bind to strictly defined molecules playing a crucial role in the inflammatory processes [30]. The most important group of biological agents are anti-tumour necrosis factor- $\alpha$ (anti-TNF) antibodies - infliximab (IFX) and adalimumab (ADA). Infliximab is administered intravenously, 5-10 $\mathrm{mg} / \mathrm{kg}$ body weight in three doses at 0,2 , and 6 weeks as an induction therapy, and then every 8 weeks as a maintenance therapy. Adalimum$\mathrm{ab}$ is administered subcutaneously, usually in doses of $160 \mathrm{mg}$ in the first week, $80 \mathrm{mg}$ in week 2, and $40 \mathrm{mg}$ every other week until week 12 , as induction therapy, and then $40 \mathrm{mg}$ every other week as a maintenance therapy $[28,29]$. The efficacy of both drugs has been proved in many clinical trials, and it is estimated at around 50\% [31].

\section{Conclusions}

High and complex fistulas in CD continue to be a challenge to surgeons. Prolonged placement of non-cutting setons remains a "gold standard" in the palliative treatment of fistulas. Currently, definitive surgical methods of treatment combined with medical measures are emerging. However, most of them require further evaluation in clinical trials.

\section{Conflict of interest}

The authors declare no conflict of interest.

\section{References}

1. Penner A, Crohn BB. Perianal fistulae as a complication of regional ileitis. Ann Surg 1938; 108: 867-73.

2. Schwartz DA, Loftus EV Jr, Tremaine WJ, et al. The natural history of fistulizing Crohn's disease in Olmsted County, Minnesota. Gastroenterology 2002; 122: 875-80.

3. Parks AG. Pathogenesis and treatment of fistula-in-ano. $\mathrm{Br}$ Med J 1961; 1: 463-9.

4. Marks CG, Ritchie JK, Lockhart-Mummery HE. Anal fistulas in Crohn's disease. Br J Surg 1981; 68: 525-7.

5. Parks AG, Gordon PH, Hardcastle JD. A classification of fistula-in-ano. Br J Surg 1976; 63: 1-12.

6. Schaefer O, Lohrmann C, Langer M. Assessment of anal fistulas with high-resolution subtraction MR-fistulography: com- parison with surgical findings. J Magn Reson Imaging 2004; 19: 91-8.

7. Alexander-Williams J, Buchmann P. Perianal Crohn's disease. World J Surg 1980; 4: 203-8.

8. Fry RD, Shemesh El, Kodner IJ, Timmcke A. Techniques and results in the management of anal and perianal Crohn's disease. Surg Gynecol Obstet 1989; 168: 42-8.

9. Hellers G, Bergstrand O, Ewerth S, Holmström B. Occurrence and outcome after primary treatment for anal fistulae in Crohn's disease. Gut 1980; 21: 525-8.

10. Pritchard TJ, Schoetz DJ, Roberts PC, et al. Perirectal abscess in Crohn's disease. Dis Colon Rectum 1990; 33: 933-7.

11. Thornton M, Solomon MJ. Long-term indwelling seton for complex anal fistulas in Crohn's disease. Dis Colon Rectum 2005; 48: 459-63.

12. Kronborg $\mathrm{O}$. To lay open or excise a fistula-in-ano: a randomized trial. Br J Surg 1985; 72: 970.

13. Williams JG, Rothenberger DA, Nemer FD, Goldberg SM. Fistula-in-ano in Crohn's disease. Results of aggressive surgical treatment. Dis Colon Rectum 1991; 34: 378-84.

14. Levien DH, Surrell J, Mazier WP. Surgical treatment of anorectal fistula in patients with Crohn's disease. Surg Gynecol Obstet 1989; 169: 133-6.

15. Michelassi F, Marcovalerio M, Rubin M, Hurst R. Surgical treatment of anorectal complications in Crohn's disease. Surgery 2000; 128: 597-603.

16. Sandborn WJ, Fazio VW, Feagan BG, Hanauer SB; American Gastroenterological Association Clinical Practice Committee. AGA technical review on perianal Crohn's disease. Gastroenterology 2003; 125: 1508-30.

17. Buchmann P, Keighley MR, Allan RN, et al. Natural history of perianal Crohn's disease. Ten year follow-up: a plea for conservatism. Am J Surg 1980; 140: 642-4.

18. Williams JG, MacLeod CA, Rothenberger DA, Goldberg SM. Seton treatment of high anal fistulae. Br J Surg 1991; 78: 1159-61.

19. Eitan A, Koliada M, Bickel A. The use of the loose seton technique as a definitive treatment for recurrent and persistent high trans-sphincteric anal fistulas: a long-term outcome. J Gastrointest Surg 2009; 13: 1116-9.

20. Edwards CM, George BD, Jewell DP, et al. Role of a defunctioning stoma in the management of large bowel Crohn's disease. Br J Surg 2000; 87: 1063-6.

21. Wolff BG, Culp CE, Beart RW Jr, et al. Anorectal Crohn's disease. A long-term perspective. Dis Colon Rectum 1985; 28 : 709-11.

22. Joo JS, Weiss EG, Nogueras JJ, Wexner SD. Endorectal advancement flap in perianal Crohn's disease. Am Surg 1998; 64: 147-50.

23. Cintron JR, Park JJ, Orsay CP, et al. Repair of fistulas-in-ano using fibrin adhesive: long-term follow-up. Dis Colon Rectum 2000; 43: 944-50.

24. O'Riordan JM, Datta I, Johnston C, Baxter NN. A systematic review of the anal fistula plug for patients with Crohn's and non-Crohn's related fistula-in-ano. Dis Colon Rectum 2012; 55 : 351-8.

25. Meinero P, Mori L, Gasloli G. Video-assisted anal fistula treatment: a new concept of treating anal fistulas. Dis Colon Rectum 2014; 57: 354-9. 
26. Yassin NA, Hammond TM, Lunniss PJ, Phillips RK. Ligation of the intersphincteric fistula tract in the management of anal fistula. A systematic review. Colorectal Dis 2013; 15: 527-35.

27. Bemelman WA. Vacuum assisted closure in coloproctology. Tech Coloproctol 2009; 13: 261-3.

28. Van Assche G, Dignass A, Reinisch W, et al. The second European evidence-based consensus on the diagnosis and management of Crohn's disease: special situations. J Crohn's Colitis 2010; 4: 63-101.

29. Łodyga M, Eder P, Bartnik W, et al. Wytyczne Grupy Roboczej Konsultanta Krajowego w dziedzinie Gastroenterologii i Polskiego Towarzystwa Gastroenterologii dotyczące postępowania z pacjentem z chorobą Leśniowskiego-Crohna [Polish]. Prz Gastroenterol 2012; 7: 317-38.

30. Mandel MD, Miheller P, Mullner K, et al. Have biologics changed the natural history of Crohn's disease? Dig Dis 2014; 32: 351-9.

31. Schnitzler F, Fidder $H$, Ferrante $M$, et al. Long-term outcome of treatment with infliximab in 614 patients with Crohn's disease: results from a single-centre cohort. Gut 2009; 58: 492-500.

Received: 8.11.2014

Accepted: 30.12 .2014 